\title{
Article
}

\section{Recovery and Movement: Allegory and 'Journey' as a means of exploring recovery from substance misuse}

Roy, Alastair Neil and Manley, Julian

Available at http://clok.uclan.ac.uk/17585/

Roy, Alastair Neil ORCID: 0000-0002-4807-7352 and Manley, Julian ORCID: 0000-0003-2548-8033 (2017) Recovery and Movement: Allegory and 'Journey' as a means of exploring recovery from substance misuse. Journal of Social Work Practice, 31 (2). pp. 191-204. ISSN 0265-0533

It is advisable to refer to the publisher's version if you intend to cite from the work. http://dx.doi.org/10.1080/02650533.2017.1305336

For more information about UCLan's research in this area go to http://www.uclan.ac.uk/researchgroups/ and search for <name of research Group>.

For information about Research generally at UCLan please go to http://www.uclan.ac.uk/research/

All outputs in CLoK are protected by Intellectual Property Rights law, including Copyright law. Copyright, IPR and Moral Rights for the works on this site are retained by the individual authors and/or other copyright owners. Terms and conditions for use of this material are defined in the policies page.

\section{CLoK}

Central Lancashire online Knowledge www.clok.uclan.ac.uk

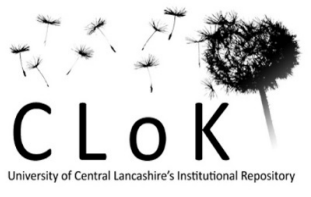




\section{Biographies}

Alastair Roy is Co-Director of the Psychosocial Research Unit, University of Central Lancashire. With a professional background in detached youth work he has a particular interest in the development of psychosocial and psychosocietal approaches to research. Between 2013-2016 he led an ESRC funded Knowledge Transfer Partnership which explored the implementation of a recovery oriented model of substance misuse treatment in Lancashire. He is Associate Editor for the journal Qualitative Social Work.

Julian Manley was educated at the Universities of Cambridge, Middlesex and West of England and holds an MSc and PhD in Psychosocial Studies. He works at the Psychosocial Research Unit, University of Central Lancashire. Recent publications include work on the social dreaming matrix and visual matrix. He was funded by the Richard Benjamin Trust to conduct visual matrix research into substance misuse that provides the data for this article. He is a Trustee of the Gordon Lawrence Foundation for the Promotion of Social Dreaming, Head of its Academic Research Committee, and member of the Executive Committee of the Climate Psychology Alliance.

Dr Alastair Roy (corresponding author)

Research Fellow

Psychosocial Research Unit

School of Social Work, Care \& Community, University of Central Lancashire

Preston PR1 2HE

UK

ANRoy@uclan.ac.uk 


\title{
RECOVERY AND MOVEMENT: ALLEGORY AND 'JOURNEY' AS A MEANS OF EXPLORING RECOVERY FROM SUBSTANCE MISUSE
}

\author{
Alastair Roy and Julian Manley
}

\section{Acknowledgments}

This work was supported by the Richard Benjamin Trust under Grant number RBT 1305. We acknowledge the support and contribution of everyone at Fallen Angels and the support of Tim Lamford from the University of Central Lancashire who supported the analysis of the movement data.

\begin{abstract}
,
The paper explores the quality of the affective and embodied experiences of a group of people in recovery from substance misuse as part of their involvement with dance and movement workshops provided by the Fallen Angels Dance Theatre. In the research we used the visual matrix method alongside individual and groupbased movement sessions so as to explore associations and affect emerging from the visual matrix. We question the frequently used metaphor of the 'journey' in recovery and suggest 'allegory' to be more apt. The linearity implied in journey contrasts with movements - both inner and outer - that are 'nomadic', 'wayfaring' and 'rhizomatic', focussed on affect and experience rather than targets and outcomes. We conclude that people working in the field of recovery and other areas of social work may wish to reconsider the value of embodiment in movement, relationship and affect when working with the experience of vulnerable people.
\end{abstract}

Key words: Recovery, journey, allegory, substance misuse, movement , dance

\section{'Journeys', directions, and destinations}

This paper is concerned with the work of Fallen Angels Dance Theatre (FADT), which exists 'to support those in recovery from addiction, to transform their lives, and to share recovery journeys with the wider public, through dance, performance and creativity.' (FADT website). In this paper, we wish to question the common use of the word 'journey' to describe a person's recovery from substance misuse. 'Journey' implies direction and destination, along with an 
implication of judgements about the right or wrong paths a person may follow in her 'journey' of recovery from substance misuse. We suggest that the idea of 'journey' is unhelpful as a description of what happens in the work of FADT, and that it may also be inappropriate as a general metaphor for recovery. Instead of 'journey', we will be suggesting 'allegory' as a description of the process of recovery, especially as a description of the experience of working with FADT. For FADT, dance and movement seek to raise the awareness of experience amongst those it works with. This experience of movement of the body is not a journey, since it leads to no place. In the work of FADT, movement is way of exploring experience in the world, where the purpose of movement is not directed towards reaching a certain destination or terminus, but used to bring what happens along the way into memory and 'conscious awareness' (Ingold 2010, pp. 152 and 126-7).

We worked over two sessions with a group of people in recovery who were regularly attending workshops run by FADT in Liverpool, UK. We used the visual matrix method, which has been employed before in the context of recovery (Manley et al. 2015; Manley and Roy, 2017) and in other contexts (Froggett et al 2015; and see Liveng et al. and Clarke in this edition) as a way of bringing visualization and association rather than discourse to the fore in group-based reflection. In doing so, a space was created where the participants could express their embodied, affective experiences of recovery through visualisation and dance. This was a space of internal movement, internal thoughts and emotions, the 'movement inside' that could open out the possibility of relation and connection to the 'movement outside' (Manley 2013) of the dance itself. 
Although the paper focuses on recovery from substance misuse, the issues are of relevance to a broad range of health and social work practice experiences, where the language of journey - with its implicit teleology of progress - is common. The use of the journey metaphor applied to people experiencing situations of extreme vulnerability might represent a form of 'cruel optimism' (Berlant, 2011; Roy, 2017), encouraging or inadvertently coercing people towards pursuing unrealistic aspirations, with those who fail to achieve them becoming targets of systemic disapproval and anxious self scrutiny (Espeland \& Stevens, 2008). We argue instead that, to work with the reality of the fragments or ruins of people's lives through the allegorical might manifest as a form of caring and hopeful pessimism, which reaches towards a potential for self awareness and personal development.

\section{'Movement outside', dance and wayfaring}

Dance contrasts to the movement implied in 'journey'. We will be asking in this paper to what extent the experience of the body in movement is in itself and by itself an experience of recovery. In doing so, we will also question the implications of the word 'recovery', if by this is implied a destination to be arrived at. Instead of the idea of 'recovery' as journeying towards a destination, we will be reflecting upon the idea that it involves a form of 'wayfaring' (Ingold 2007a, pp. 75-84) in which someone in recovery 'negotiates or improvises a passage' as she goes along. This is what Deleuze called 'nomadology', later converted into 'nomadic theory' by Braidotti (2011). Nomadic theory conceives of thinking as embodied and embedded in the experience of self; it conceives of self as relational and nonunitary; it speaks to a turn of thought with its roots in 
post-modern continental philosophy towards affect and experience (Braidotti 2011, pp. 2-8). It also connects to the Deleuzian concept of the 'rhizome', that we use alongside the allegory to move away from the linear tendency behind the concept of journey. The rhizome describes the creation of paths without direction - the paths of the nomad - where important moments are those that come close to creativity through chance encounters and spontaneous events (Deleuze and Guattari 1988, pp. 21-15). The point for Ingold, referring to Deleuze, is that

'Life is open-ended: its impulse is not to reach a terminus but to keep on going. The spider spinning his web or the musician launching into a melody 'hazards an improvisation'. But to improvise, Deleuze continues, is to join with the World or meld with it. One ventures from home on the thread of a tune' (Ingold 2010, pp. 83-84)

\section{'Movement inside' and interrelationality}

Although actual physical dance is the essence of the recovery work of FADT, we mean more than this by 'movement'. In Braidotti's nomadic theory (2011) the concept of movement is used to suggest a quality of thought that goes beyond the Cartesian brain. According to nomadic theory, to understand movement as a means of thinking, we have to consider both the 'embodiment of the mind and the embrainment of the body (Marks 1998)' (Braidotti 2011, p. 2). Instead of focussing on each individual mind, experiential knowledge is gained though 'the relational motion of approaching multiple others' (Braidotti 2011, p. 2). 
Where 'inhabitants meet, trails are entwined, as the life of each becomes bound up with the other. Every intertwining is a knot, and the more that lifelines are entwined, the greater the density of the knot' (Ingold, 2010, p. 148). In this way human existence is not place-bound but place binding (Tilley, 2004, p. 25). Creativity and vitality emerge from the wanderings of the 'nomad' over 'smooth spaces' (meaning spaces where movements are free and without direction), and where spontaneous chance encounters produce knots or 'intensities of affect' (Deleuze and Guattari, 1988, pp. 474-500). It is in encounters such as these that the work of FADT - where recovery becomes a movement in relation to others creates new perspectives and opportunities for creative changes to occur.

In our research we were asking if this relationality and encounter with 'multiple others' in the dance work of FADT was effective in supporting recovery. Through the sharing of mental images and affect in the context of a visual matrices, we were able to compare the internal movement of images and affect that weaved in and out of the mental space of the matrix, with the movement sessions. In doing so, we became conscious of the importance of the 'nomadic' process of the visual matrix and 'the dynamic nature of thinking and the need to reinstate movement at the heart of thought by actualizing an nonunitary vision of the thinking subject' (Braidotti 2011, p.7).

\section{Allegory, images and emergent meaning}

Through the use of the visual matrix method and the opportunity it gives participants to reflect upon experience through a dynamic encounter of images 
and affect among themselves, we are able to substitute the representational and cognitively conceived symbolism of 'journey' with the nuanced, incomplete and provisional visual fragments implied in 'allegory'. This difference is made clear in an extract from Walter Benjamin's The Origin of Tragic German Drama, which tells us that allegory 'corresponds to a perception of the world in ruins, and is therefore the art of the fragment, and the opposite of the symbol, which presupposes the value of 'Nature' preserving unchanging, complete, identities and values' (quoted in Tambling 2010, p. 110). In allegory, importance is given to the experiences of unplanned discoveries and encounters rather than preordained steps towards a final destination. This is revealed to us at the start of one of the most famous allegories in literature, Dante's Inferno: 'In the middle of the journey of our life I came to myself in a dark wood where the straight way was lost', (quoted in Tambling 2010, p. 2). We will be looking at how the images that emerged from, the visual matrix were used by the dance group as an allegory for their lives in the context of recovery, embodiment and movement. We will consider the validity of conceptualizing the experience of substance misuse as one of movement and allegory and how the use of movement and dance in the practice of FADT can lead to wellbeing and a reassessment of the meaning of living a life in recovery. Finally, we seek to understand the special nature of dance and movement with people in recovery and how movement and dance contribute to allegorical aspects of recovery that begin with the complex image of the 'Fallen Angel', the tragi-daemonic figure of recovery in FADT.

\section{The Movement to Recovery in the Treatment Sector}


Our research was undertaken against a background of a sector that has moved from broad to narrow definitions of 'recovery' and where the practice of FADT might be seen as an interesting anomaly rather than in any way mainstream. In the UK since about 2005 there has been a steady move towards a recovery orientation in policy and practice. In early discussions - led by UK Drug Policy Commission in (2008) - about the ways in which a recovery orientation might inform treatment approaches and models of care, there was a desire to reflect the highly personal and idiosyncratic nature of addiction. This seemed to reflect a desire amongst many leaders in the sector to resist the possibility that a very generalising definition of recovery might be imposed by government as part of a new policy direction. By 2010 recovery had become a central strand of a new government policy and there was a stated emphasis on increasing the number of people achieving 'full recovery' (Monaghan and Wincup, 2013), reflecting a governmental desire for recovery to become a specifiable destination (Roy and Buchanan, 2015).

By 2016, a set of quantifiable measures of recovery had been produced (Neale et al 2016) and subsequently a Substance Use Recovery Evaluator tool ${ }^{1}$, which the authors suggested now made it possible to 'measure' the concept of recovery in an 'objective' and 'meaningful way'. In the development of measures and tools albeit ones co-developed with service users - we see a desire to smooth over idiosyncratic difference and to fix meaning through quantification, in which recovery becomes something that can be measured - whether by the self or

\footnotetext{
1 http://www.kcl.ac.uk/ioppn/depts/addictions/Scales,-Measures-and-Instruments/SURESubstance-Use-Recovery-Evaluator.aspx
} 
others - in an objective manner (Espeland and Stevens, 2008). Although the idea of a quantifiable set of measures by which one can self-monitor recovery progress might be alluring to some who struggle with substance misuse, appearing to provide something concrete and secure, the shadow side of this might be failure, shame and humiliation in which "The 'outliers', 'underachievers', and 'under-performers' produced by performance measures become targets of ... disapproval and anxious self-scrutiny" (Espeland \& Stevens, 2008, p. 409).

In traditional 12 step programmes the 'journey' consists of a series of definable steps which are accompanied by a sense of a spiritual journey towards some form of redemption, akin to enlightenment. Although theoretically this is a journey which can have no endpoint or final destination - because in the Fellowships one is always a self-confessed addict - it is one measured in time travelled, in the public voicing of days since last use. It could also be argued that the 'journey' does in fact end in abstinence with a constant fear of 'falling' again. In 1961 Carl Jung wrote a letter to AA's co-founder in which he set out two main ways in which people with serious alcohol addiction might recover. One was through "real religious insight", the other was through "the protective wall of human community" which included "personal and honest contact with friends" (AA, 1963 cited in Kelly et al. 2012, p. 296). Kelly et al (ibid) suggest that "although AA has more earnestly expressed the former as being the principal pathway to recovery ... perhaps inadvertently, stemming from its social orientation and structure, it has tapped also into the curative facets of the latter protective and positive social influence" (p. 8). This helps frame the issues 
affecting people with substance misuse problems around human relationships rather than belief systems, steps or targets (Roy and Buchanan, 2015).

\section{Trauma, Knowing and Recovery}

Taking into account the importance of relationships and embodied experience to recovery, we argue that a bio-psycho-social view of addiction seems relevant in engaging with a project such as FADT, which emphasizes the long term benefits of immersion in a community of fellow addicts. A great deal of research has confirmed a link between childhood experience of trauma and subsequent addiction. The attraction of drugs - initially at least - can lie in the ways in which they fix problematic feeling states in individuals, providing a sort of protective function which can create a powerful motive for continued use. This emphasizes the idea that abstinence by itself might be insufficient in addressing substance misuse problems, because it addresses the coping strategy rather than the issue which led to its emergence. This opens out the possibility that the 'restlessness, paranoia and hypersensitivity' which often accompany both addiction and the early phases of recovery might be 'a body's testimony to its past' (Gunaratnam 2015) and one that needs to be revealed through the expression of embodied knowledge through relationship in movement, which is the very essence of the work of FADT.

We are interested, therefore, in exploring the idea that to know the self in addiction and recovery may well be the stuff of experience rather than 
intellectual knowing. The discussions we had with dancers at FADT brought to life the ways in which people in addiction can feel separated from others in the world; and that bodily knowing - undertaken in relationship with others - might be important in pursuing a knowing-recovery and establishing a connection with the world. Ingold (2010) makes a distinction between the quality of knowing through experience and the accumulated knowledge of cognition, arguing:

To be sure, the expert is more knowledgeable than the novice. What distinguishes them, however, is not a greater accumulation of mental content - as though with every increment of learning yet more representations were packed inside the head - but a greater sensitivity to cues in the environment and a greater capacity to respond to these cues with judgment and precision. The difference, if you will, is not one of how much you know but how well you know.

The work of FADT recognizes that successful recovery is not predicated on the acquisition of 'built-up' knowledge ('mental content'), but is based on a form of corporeal and embodied understanding which is built in the environment and through movement (O’Neill, 2014; Roy 2016). People in recovery don't apply knowledge learned elsewhere to their daily recovery practice, but come to know 'along the way' and 'by way of' their experience (Ingold and Kurtilla, 2000, p. 191-192).

\section{Methodology}


Since the aim of our research was to investigate movement and allegory in collaboration with FADT, we avoided methods focused on narrative, as well as methods with an a priori structure, such as semi-structured interviews and/or focus group discussions. Instead, we chose an approach - the visual matrix likely to open up spaces of reflection, affect and hypothesis. As researchers we took on the role of facilitators or hosts in the visual matrix. We made two research visits to the FADT dance spaces being used at the time. In each visit we hosted a visual matrix, eliciting images from the participant dancers and performers. There were about twelve participants, male and female, between the ages of 20 to 50, and they were accompanied by two researchers and one FADT staff member/choreographer. The participants and researchers sat on randomly distributed cushions on the studio floor, thereby avoiding direct eye contact with each other and encouraging instead a 'speaking to the space'. In the visual matrix, participants are able to express spontaneous images and feelings as they arise, free associate and make links and connections between the images, without ever interpreting meaning or entering into cognitive discussions. In this way the visual matrix accumulates a collage of affect-laden mental images that creates a shared affective sense instead of a discursive, cognitive knowledge.

Each of the two visual matrices was followed by a different movement exercise. In the first, each individual was asked to develop and perform for the group a short movement piece which related to themes from the matrix. In the second, the response consisted in a collective improvisation in which the whole group moved together in response to the visual matrix as well as in relation to one another. In each case, participant expressions in movement and dance emanated 
from the visual matrix, but in the second session they also emanated from other people's movements.

The visual matrices were audio recorded and transcribed, while the dance and movements sessions were video recorded. We worked in a series of panels to analyse the transcripts of the visual matrices and compared these to the videoed movement sessions.

\section{Allegory, movement and affect in visual matrix 1}

The following analysis comprises quotations from a selected part of the visual matrix transcript that emerged through analysis as being especially illuminating. The participant contributions are transcribed exactly as and when they arose. Sometimes they consist of one word only; at other times a series of images are expressed in a sentence or two. Each separate intervention is marked by a dash. We begin with an image of ice in the form of icicles which develops into a series of image-affects that accumulate and multiply through association:

-icicles

-support

-Brings to mind an artist who makes sculptures out of ice. They are so beautiful but they start to melt, drip by drip, and eventually, by the end of the day, they have melted away. It's both beautiful and then sad when it's gone 
The icicles that seem to be the opposite of 'support', so essential to recovery, are transformed into 'sculptures of ice' by an artist. In this way the unsupportive icicle is made into something supportive of beauty, aspiration and creativity. The agency of humankind - the 'artist' - is what makes this possible, conveying a powerful sense of the potential for creativity and therefore change. In the recovery context, the change is from a sense of melting away to something made and recognised. In this way, there is hope in the ability of each of us to create. Nevertheless, the image-affect is in no way naïve or idealistic, since even this creation is subject to erosion commensurate with the passing of time. This leads to the next association:

-I'm reminded of that hotel made of ice. They have to remake it every year, it's something that keeps rebuilding

In this case the ice construction becomes a useful shelter. Many in recovery will understand shelter as being a precarious asset. The shelter in the image-affect is a temporary one, a hotel, and rather than accept its erosion as in the previous image, in this case it is remade every year, an action that speaks to the need for continued work and perseverance as well as a facing up to reality, both qualities necessary to recovery. This brings up an association to Tibetan Buddhist sand paintings:

-Brings to mind sand art. The Tibetans or Buddhists creating mandalas in the sand and then at the end of the day they brush it up and go 
The image reaches back to the artist evoked at the beginning of the sequence of associations, building up in this way the rhizomatic sense of connections. In a sweep of creative imagination the 'ice artist' becomes the 'sand artist', within which the sense of movement creates a tension between sensations of wet/cold and dry/hot and associates the artistic creative practice with some form of spirituality suggested by Buddhism. This may help us to understand the need for some spiritual core or form of belief system to help people in recovery, and indeed the Fellowships traditionally emphasise spirituality through Christian belief. At the same time, the association moves sequentially, with the rebuilding of the ice hotel being linked to the need to rebuild the sand mandala, which has to be destroyed. The repetition of the need to persist and rebuild, but this time in tension of the two extremes of wet/cold, dry/hot, emphasises the importance of these qualities in recovery both through the repetition itself and the allencompassing extremes within which rebuilding has to occur. The powerful affect evinced at his stage of the matrix encourages the FADT choreographer, in his role as guide and mentor, to make a direct and overt link to the struggle of people in recovery:

-That brings to my mind how the Ego builds up so quickly in recovery and how you have to smash it every day, so you are rebuilding on the go every day

The next image combines the previous artist/spiritual/ice image-affects in an image of the small rocks in a Zen garden which have found their way into a man made creation of peace and serenity after being formed by a glacier. In the image 
of the Zen Garden, created for contemplations of the meaning of life, we have a further rhizomatic accumulation and synthesis of the images of water and sand, since the Zen Garden specifically imitates the ripples of water in shapes delineated in sand or gravel:

-A friend of mine has a garden and small rocks in it, like a Japanese Zen garden style. They are stones from a glacial shift.

The fact that the stones come from a 'glacial shift' reminds us of the ice of the previous images and adds to their sense by turning what was originally a dripping icicle into a source of grinding power that has the capability of moulding stones into beautiful rounded objects that can subsequently be used for a Zen Garden.

Following this contemplative 'movement inside' implied in the meditation of a Zen Garden, the next associations remind us of the great distance, the 'movement outside', that has to be covered - even if it is in a slow, grinding movement - for a stone to be hewn into a shape, from some mysterious place lost in the past to Birmingham!

-You don't know how far they have travelled. In the long journey, and how they have been rounded -They start somewhere and they snake along and they are all taken down to somewhere else, could come to somewhere else, like Birmingham 
In this way the physical movement, which is unknown in distance and has moved according to the whim of natural forces rather than to a set purpose and direction, is linked up with the internal movement of meditation and self reflection, where thoughts are allowed to flow rather than conducted towards a specific problem. In both cases, we have an example of nomadic activity, which has specifically emerged from the thinking and affective space of the visual matrix. In terms of recovery, there is an appeal to creativity and movement that provides creativity as a means of reaching a space where recovery is made more possible than in situations of cognitive decision-making, target setting and programme design. As we have suggested above, it is precisely this kind of relational and somehow abstract knowledge that seems to work in the Fellowships (Kelly et al. 2012).

\section{Allegory, movement and affect in visual matrix 2}

One of the striking features of the second visual matrix was the exploration of the importance of the endurance of love in the passing of time, which is explored in images of water and wood. Once again, the movement of water, and whether this movement is free or restricted, is key to this reflection. This emerges from the very beginning of the matrix, where an immediate contrast is made between free flow and channeled flow:

-Strong images of water, water running down rocks and though the city. Then an image of a bridge. Water running through and a concrete sluice. 
The channelling of the water seems to occur after the image of a bridge marking a 'before-and-after', and a sense of a loss of freedom. The sense of channelling life is expressed in an image of people following cracks in the pavement which are contrasted to ripples in the water and the added suggestion that the lack of footprints and therefore a sense of direction in movement, may be due to the action of the waves, 'water coming in and out':

-No footprints.

-People walking in and out of each other, like busy ants in the cracks of the pavement.

-Don't step on the cracks.

-Watching ripples.

-Waves coming in and out.

The reference later in the visual matrix to the mother's tears which is associated to an earlier image of a frozen tear, links the image of moving water to a tear of happiness, which is always in danger of becoming stilled through freezing:

-I have an image of my mum crying a single tear, a tear of happiness, watching it run, flowing and trickling on all the lines of her face and dispersing.

Later in the matrix, the relative stillness of a tree trunk is contrasted to the passing of time for two people in love; yet the quality of this love somehow resists the movement of time: 
-Reminds me of an image of a $19^{\text {th }}$ Century painting, where two old lovers are standing next to a tree, but the tree has aged, as the lovers have, and they can see their names etched on the trunk, so you can see the passing of time as the names have aged with the tree.

-Image of an older couple and the love is still there, strange. They look tired and worn out but they are still together.

The water and tree images are connected in rhizomatic fashion by an image that expresses the wearing away of wood by water, eventually distorting the former usefulness of the object:

-Desolate, water-aged rotten wood that served a purpose.

What is striking about the way these image-affects work - according to a nomadic, rhizomatic collage of interlinked associations - is the way the complexity of existential human concerns, such as love and time can be brought to light and made relevant to the lives of the participants in FADT. Through understanding the value and importance of an enduring love in terms of support to the participants in the matrix, a space of autonomy and empowerment is created for those participating in the matrix. They themselves are reflecting upon and identifying their own values through self-reflection instead of being advised or told by a third party who may be knowledgeable but inevitably distant to the experience of the individual in recovery. 


\section{The allegory of movement}

The two visual matrices developed combinations of image-affects that together gave expression to the complexity of people's experience in recovery. The nature of this expression as a series of loosely attached image-affects oscillates between what Derrida called 'constative' and 'performative' iterations, the former being a 'discovering or unveiling' and the latter a 'producing, instituting, transforming' (Derrida 1991, p. 206). The image-affects of the matrix have produced an 'essential instability' (ibid, p. 207) that comes from the shifting complexities of the language focus that Derrida would have called 'deconstruction'. The visual matrix works in a way that is similar to Derrida's description of fable or allegory in his essay 'Psyche: Inventions of the Other' (ibid). What can at first be 'perfectly normal in its grammar, spontaneously deconstructs the oppositional logic that relies on an untouchable distinction between the performative and the constative and so many other related distinctions' (ibid, p. 208). For example, the smoothing of the rock into pebbles by glacial action that are then deposited in 'Birmingham' is not so much a story of glacial erosion as an expression of the affect contained in the quasi-symbolisation of beauty, perseverance, and change against all odds achieved through gradual transformation (rough rock to smooth pebble); and then, through association, these pebbles, gravel and sand are made into a Zen Garden, a symbol of inner peace and quiet meditation. The shared nature of the hope and yearning desire implied in this transformation is, in normal circumstances, emotionally and conceptually difficult to express, especially for people in the midst of the anxieties and emotional upheavals that are part and parcel of the experience of recovery. 
Working with the visual matrix and dance movement created a shared space for the exploration and expression of these allegories in the first matrix. Similarly, existential concepts of time and love, which are perhaps not uppermost in standard discussions between people in recovery and staff from supporting agencies, emerged as important themes in the second visual matrix.

C.S Lewis' seminal work The Allegory of Love, (1936), describes the use of allegory as an exploration of the complexities of love. Lewis pointed out how medieval texts always operated on two levels, a superficial narrative or story level accompanied by a sub-text of rich, loosely connected images and symbols that were representative of emotional realities which were not necessarily part of the sequential actions of the narrative. These loosely connected allegorical images are dependent for their meaning to emerge on a free-flowing movement between the related parts. In our research, we saw how this kind of movement inside the 'body' of the space of the visual matrix was replicated in the movement and dance work of FADT. In one interesting contrast, we noted how the movement of the dance interpretations from the dancers was different in the two sessions we participated in. The first, which was framed around individual performance, led to story-like performances, which captured a singular theme for example a metamorphosis. The second, framed around an improvised, simultaneous group exploration, began with loosely connected individual movements, which later became intensified as they were brought into relation and interaction with those of others in the group. In this way, the second movement session somehow mirrored the rhizomatic interconnectivities of the visual matrix by extending the sense of the image-affects into bodily movement, 
allowing for a continuation - in movement - of the complex and overlapping exploration of the matrix. This sense of rhizomatic interconnectivity and how this emerges from associations rather than sequential narrative was noted by one of the participants in the second session:

Associations, my brain is a big joined up spaghetti (Participant, FADT)

In both the movement improvisation exercises and the inner 'movement' of the affect in the matrix the relational and sharing process takes sensation away from being a purely subjective, personal experience to another understanding of 'body', the body of inter-connected and related forces:

Sensation in the body does not belong to the subject. Sensation or feeling belongs rather to a sensibility of forces that is expressed in the genesis and emergence of their relations with one another... affect and sensation are thus discerned in the body, in each body, but also in the context of other, emerging bodies... (Rothfield 2011, p. 211)

The idea of such a shared affective space as that which is experienced in dance improvisation and the sharing of image-affects in a visual matrix, is a powerful way of understanding the value of bonding and sharing among peers. Given the relationship we identify between trauma and addiction and the tendency to use substances to fix feeling states such as personal anxiety, it is easy to see why people pursuing recovery might benefit from the movement activities of FADT. 
Recovery, our research suggests, has more to do with companionship, relationships, bonding, creating safe spaces and spirituality rather than a dogged pursuit of quantifiable targets and goals. Our research indicates that it is the embodied joy of inner and outer movement in relation to the self and others that makes the FADT programme so attractive and beneficial to participants. We can see this effect in the following comment from another participant who described the experience of combining the image-affects of the visual matrix with movement as being at once creative, intuitive and spiritual:

Loved it - Felt in touch with pure creativity, intuition. Felt like a spiritual exercise.

(Participant, FADT)

Spirituality, intuition, 'pure creativity' and a sense of absolute joy are not necessarily commonly valued features in substance misuse programmes, which instead might be more concerned with quantifiable and objective measures of things such as substance misuse, self-care, relationships and outlook on life. Approaches based on measurement are all associated with the journey metaphor we began this article with. This is an attitude with its roots in Cartesian reason and logic, which favours the simplification and reduction of emotional material into sequential narratives of cause and effect. As we see in our work, these cannot do justice to the complexities of the experience of recovery. Instead, we have drawn on the idea of an 'allegory of movement' as a broad descriptor of the complexities of recovery experience. 
This is also applicable to practice in social work and health care in which practitioners must often work with people in situations of extreme uncertainty, in which 'practices are more analogous with art forms of music and dance than the rationalities of conscious thought' (Gunaratnam, 2015, p. 7). She cites Deleuze who suggests

It is by speed and slowness that one slips in among things, that one connects with something else. One never commences; one never has a tabula rasa; one slips in, enters in the middle; one takes up or lays down rhythms.

To borrow from Ingold (2010) we argue that recovery is open-ended: its impulse is not to reach a terminus but to keep on going. The work of FADT, encourages the dancer to launch into a movement, to 'hazard an improvisation'. This is a deconstructed world of care which needs to be approached in its own terms. It is a world understood in terms of affective relationships in a state of constant movement and interchange. Ultimately, and vitally the work of FADT creates a space for each individual's world to join in with the World that we all share.

\section{References}

Berlant, L. (2011) Cruel Optimism. North Carolina: Duke University Press. Braidotti, R. (2011) Nomadic Theory. New York: Columbia University Press Deleuze, G. and Guattari, F. (1988) A Thousand Plateaus. London: Continuum. 
Derrida, J. (1991) 'Psyche: Inventions of the Other' in Kamuf, P. (ed) A Derrida Reader. Between the Blinds. New York: Columbia University Press.

Espeland, W.N. and Stevens, M.L. (2008) A sociology of quantification, in The European Journal of Sociology 49(3): 401-436.

Ingold, T. (2011) Being Alive: Essays on Movement, Knowledge and Description. London: Routledge.

Ingold, T., and T. Kurtilla (2000) Perceiving the environment in Finnish Lapland. Body and Society 6,

no. 3/4: 193-196.

FADT - http://www.fallenangelsdancetheatre.co.uk

Froggett, L., Manley, J. and Roy, A. (2015) The Visual Matrix Method: Imagery and Affect in a Group-based Research Setting. Forum Qualitative Sozialforschung / Forum: Qualitative Social Research, 16 (3).

Gunaratnam, Y. 2015. Death and the migrant: Bodies, borders and care. London: Bloomsbury.

Hughes, J., A. Roy, and J. Manley. 2014. Surviving in Manchester: Narratives on movement from the Men's room, Manchester. London: Lankelly Chase Foundation.

Kelly, J.F., Hoeppner, B., Stout, R.L. and Pagano, M. (2012) Determining the relative importance of the mechanisms of behavior change within Alcoholics Anonymous: A multiple mediator analysis, in Addiction 107(2): 289-299.

Lewis, C.S. (1936) The Allegory of Love. Oxford: Oxford University Press

Manley, Julian (2009) 'When words are not enough'. In Clarke, S. \& Hoggett, P. (eds) Researching Beneath the Surface. Ch. 4 pp. 79-98. London: Karnac Books.

Manley, J, (2013), 'Movement Inside, Movement Outside: the Arts, Creativity and Sport' in Doug Sandle, Jonathan Long, Jim Parry and Karl Spracklen, (eds.) Fields of Vision: The Arts in Sport, LSA Publication No. 125

Manley, J., Roy, A. and Froggett, L. (2015) Researching recovery from substance misuse using visual methods. In: L. Hardwick, R. Smith, and A. Worsley (eds) Innovation in Social Work Research. London: Jessica Kingsley, pp. 191-211.

Manley, J. \& Roy, A. (Forthcoming 2017) Researching recovery from alcohol and substance misuse using visual methods with FADT Dance Theatre. In: Niven, K., Lewis, S. \& Kagan, C. (eds.) Social Impact: Making a Difference with Psychology. London: RBT

Marks, J. (1998) Gilles Deleuze: Vitalism and Multiplicity. London: Pluto 
Neale, J., Panbianco, D., Finch, E., Marsden, J., Mitcheson, L., Roe, D., Strang, J. and Wykes, T. (2016) Emerging consensus on measuring addiction recovery: Findings from a multistakeholder consultation exercise, in Drugs: Education Prevention and Policy 23(1) 31-40.

O’Neill, M. 2014. Participatory biographies: Walking, sensing and belonging. In Advances in biographical methods: Creative applications, eds. M. O’Neill, B. Roberts, and A. Sparkes, 73-89. London: Routledge.

Roy, A. (2017) Recovery as cruel optimism: Exploring recent responses to substance misuse through policy, practice and lived experience. ESRC - Complex Needs to Disordered Personalities: Political Discourses and Practice Responses, 17th Janaury 2017, The Foundry, Vauxhall, London.

Roy, A. (2016) Learning on the move: exploring work with vulnerable young men through the lens of movement, in Applied Mobilities 1(2): 207-218.

Roy, A. and Buchanan, J. (2015) The Paradoxes of Recovery Policy: Exploring the Impact of Austerity and Responsibilisation for the Citizenship Claims of People with Drug Problems. Social Policy and Administration 50(3): 398-413.

Rothfield, P. (2011) Dance and the passing Moment: Deleuze's Nietzsche. Chapter 10 in Guillaume, L. and Hughes, J. (eds) Deleuze and the Body. Edinburgh.

Edinburgh University Press. pp. 203-224

Tambling, J. (2010) Allegory. London: Routledge

UK Drug Policy Commission (2008) The UK DPC Recovery Consensus Group: A Vision of Recovery. Policy Report. July 2008, London.

www.ukdpc.org.uk/wp-content/uploads/PolicyreportAvisionofrecovery_UKDPCrecoveryconsensusgroup.pdf 